\title{
Mechanical behavior of steel reinforcement before and after flame spray coating in marine environment
}

\author{
Maria Basdeki $^{1 *}$, Konstantinos Koulouris ${ }^{1}$ and Charis Apostolopoulos ${ }^{2}$ \\ ${ }^{1} \mathrm{PhD}$ candidate, Civil Engineer, Department of Mechanical Engineering and Aeronautics, University \\ of Patras \\ ${ }^{2}$ Professor, Dr. Ing. Civil Engineer, Department of Mechanical Engineering and Aeronautics, \\ University of Patras
}

\begin{abstract}
Corrosion of steel reinforcement is a major concern for durability of Reinforced Concrete (RC) infrastructure. In particular, corrosion of reinforcement raises important issues for reinforced concrete design and assessment, since it can impair not only the appearance of the structure, affecting the cross sectional area of reinforcement with the subsequent degradation of strength and ductility properties of steel and, ultimately, structural integrity of each structure. As it is widely known, international scientific community up to date, used various methods so as to increase the corrosion resistance of steel. In this context, in the present study, specimens of steel reinforcing bars - B500c class- were examined after flame spray coating with an alloy of aluminum and zinc, without any interference in the chemical composition or in the production mode. More specifically, bare rebars of $12 \mathrm{~mm}$ nominal diameter were subdivided in two groups, in reference - as delivered - conditions and after flame spray coating; both groups of rebars were subjected to accelerated corrosion experiments, using impressed current technique, and subsequently their mechanical behavior in uncorroded and corroded conditions. The outcomes attained from the experimental study indicate a positive contribution of this method compared with other studies. Moreover, a comparison is presented between the present study on flame spray coating and our recent studies on application of anticorrosive coatings, such as shot peening treatment.
\end{abstract}

\section{Introduction}

As it is widely known, the long-term performance of reinforced concrete is assessed via two main criteria, serviceability and durability. Serviceability relates to the ability of the element to sustain loads throughout its life and perform its intended function. Durability refers to the ability of the material to resist changes in its microstructure and properties, particularly where such changes may adversely affect the serviceability of the element. However, the durability of RC structures is unfavorably affected due to corrosion of steel reinforcement, since it degrades the mechanical properties of materials and, mainly, the

* Corresponding author: mbasdeki@upnet.gr 
ductility, which plays the key role so as to ensure the bearing capacity of elements and therefore the whole structural performance in earthquake prone areas.

In coastal regions, where the prevailing high temperature is combined with high concentration of chlorides, the corrosion phenomena are intense and constitute the major degradation factor for reinforced concrete structures. Moreover, strong earthquakes cause high plastic deformation amplitudes beyond the elastic limit. In the presence of corrosion structures seem to demonstrate values of deformation below the minimum requirements imposed by standards, and this remains a concern for reinforcing bars' capacity. Hence, the mechanical properties of reinforcing bars are crucial parameters for the anti-seismic resistance of RC structures.

From a financial perspective, corrosion is a considerable challenge and one of the most significant costs faced across the world, with enormous costs for repairing damaged structures (Figure 1), indicated by several reports, [1-3].

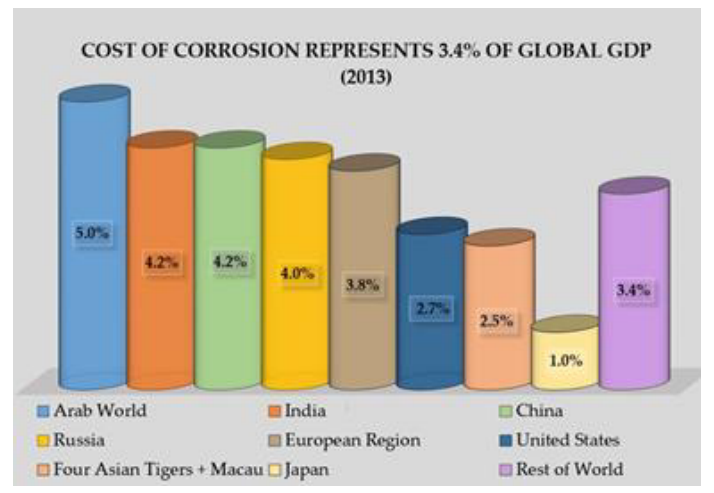

Fig. 1. Global costs of corrosion.

In that sense, many researchers have studied corrosion phenomena and quantified their adversary consequences in terms of material, cross-section and element, so as to assess the structural integrity of corroded RC structures. Notably, scientific works have highlighted that corrosion factor is liable for the reduced cross-sectional area of steel reinforcement and the drop of its mechanical properties [4-7], the recurrence of cracking and spalling of the cover concrete, which leads to deterioration of steel - concrete interface and, subsequently, to bond loss between them [8-11]. Furthermore, RC elements subjected to corrosion phenomena demonstrated degraded bearing and rotational capacity [7, 12-13].

Yet, the established fact that steel bars are inherently sensitive to corrosive environments, has prompted the use of protective surface coatings, namely an effective way of extending the limits of materials at the upper end of their performance capabilities, by allowing the mechanical properties of substrate materials to be maintained [14]. Aluminum, zinc, and their alloys are commonly used as cathodic protection materials due to their relative good corrosion resistance and sufficient negative potential. Simultaneously, the techniques of anodic coating, such as thermal spraying (Figure 2), have been greatly promoted, as several studies have been conducted [15-18]. 

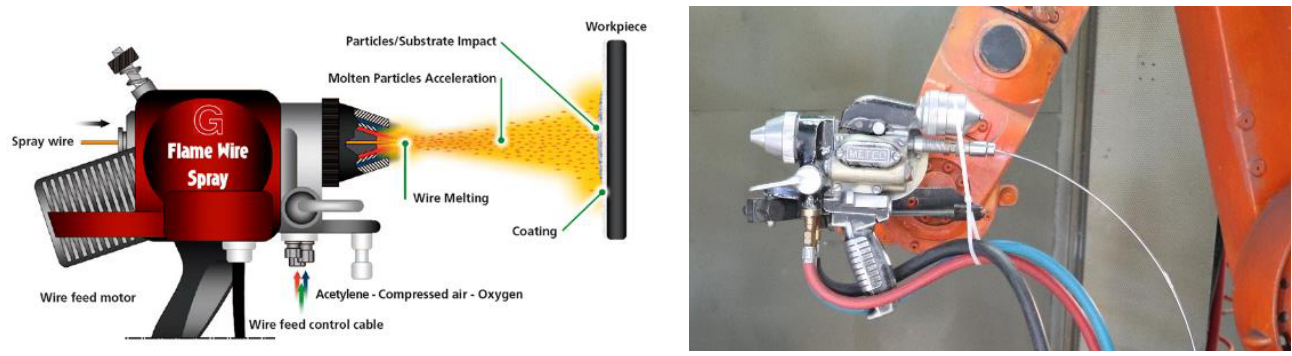

Fig. 2. (A) General schematic diagram of thermal spray coating processes and (B) Thermal spray coating set-up

The need for confronting the problem of resistance of reinforcing steel bars against corrosion is an issue of great importance and a perpetual challenge to the structural integrity and reliability of RC structures. The present study is a part of an ongoing research which focuses on the investigation of the effect of thermal spray coating to steel reinforcement towards corrosive factor.

\section{Experimental procedure}

In the present manuscript, an effort has been made to increase the corrosion resistance of the high strength and ductility dual-phase steel B500c class, with the use of thermal spray Zn85A115 coating, without any interference in the chemical composition or in the production mode. In order to examine the corrosion resistance of the material, accelerated corrosion tests were carried out in salt spray chamber. Upon completion of the corrosion tests, tensile tests were performed to assess the mechanical performance of modified samples of steel reinforcement.

\subsection{Specimen geometry and materials}

The experiments of this study were conducted on ribbed steel reinforcing bars of $8 \mathrm{~mm}$ nominal diameter and of B500c class. The chemical composition of steel B500c is given in Table 1. Totally, forty eight specimens were cut, each with a total length of $350 \mathrm{~mm}$ and exposed to corrosion length equal to $250 \mathrm{~mm}$, with the rest of rebar's length protected with a wax layer, as it is shown in Figure 3. The rebars were subdivided into two groups, coated and bare specimens; the first group of samples had a protective layer of $80-120 \mu \mathrm{m}$ was created using an acetylene fuel flame spray machine, with wire feed by zinc $(85 \%)$ and aluminum (15\%). and the other test group was consisted of simple (bare) steel bars without coating.

Table 1. Chemical composition of reinforcing steel (\% by wt.).

\begin{tabular}{|c|c|c|c|c|}
\hline Element & C & Mn & Si & Cr \\
\hline \% by wt. & 0.21 & 1.04 & 0.2 & 0.17 \\
\hline
\end{tabular}



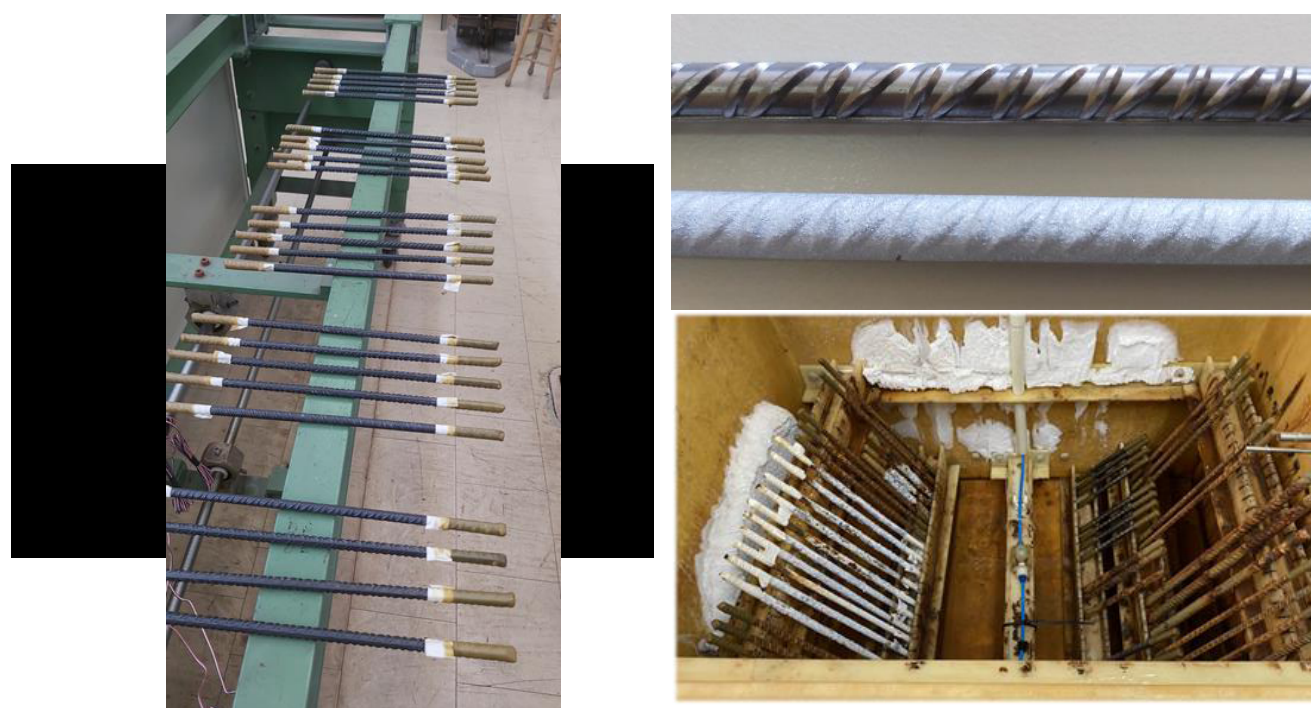

Fig. 3. (A) Preparation of the specimens (B) depiction of the B500c steel before and after coating (C)

\subsection{Accelerated corrosion technique}

Since corrosion phenomenon is a slow natural process, in order to have faster results, each group of rebars was subjected to artificial accelerated corrosion.

All samples of bare and coated steel bars were cleaned and weighed, prior to the experimental process. The salt spray laboratory corrosion was conducted in a special salt spray chamber, in accordance with ASTM-B117 standard [19], for different exposure times, namely 30, 60 and 90 days. During the corrosion test experiment the specimens were sprayed with a $5 \%$ sodium chloride $(\mathrm{NaCl})$ solution by the weight of water and $\mathrm{pH}$ ranging between 6.5 and 7.2 , switching $8 \mathrm{wet} / \mathrm{dry}$ cycles a day, at $35^{\circ} \mathrm{C}$ temperature as shown in Figure 3. After the exposure, the specimens were cleaned according to and the oxide layer was removed from the specimens' surfaces using a bristle brush, according to the ASTM G1-03 [20], so as to estimate the level of corrosion damage.

\subsection{Mechanical Tests}

Upon the completion of accelerated corrosion process, monotonic tests were carried out on non-corroded and corroded specimens, of both subcategories, according to the ISO 15630-1 Standard [21]. For the tests, a servohydraulic MTS $250 \mathrm{kN}$ machine was used, the employed displacement rate was set to $2 \mathrm{~mm} / \mathrm{min}$. The mean values of yield stress $\left(R_{p}\right)$, tensile strength $\left(R_{m}\right)$ and plastic strain at maximum force $\left(A_{g}\right)$ were determined, after three tests for each category.

\section{Results - Discussion}

In light of the fact that tensile test is considered as the initial assessment tool to classify different types of materials and subsequently steel reinforcement, either in terms of yield strength $R_{p}$ and tensile strength $R_{m}$ or in terms of deformation $A_{g}$. Current regulations determine the design and analysis of RC structures, based on the determined abovementioned values. The results of the experimental work are summarised in the 
aforementioned Figures 4, 5 and 6. In particular, the outcomes are demonstrated forthwith with results from previous experimental studies, in comparison to the shot blasting process [22-23].

The recorded values are presented in detail in the following Table 3.

Table 3. Percentage Mass Loss of Bare and Coated Specimens.

\begin{tabular}{|c|c|c|c|}
\hline \multirow{2}{*}{$\begin{array}{c}\text { Corrosion } \\
\text { time }\end{array}$} & Bare & Coated (Zn85Al15) & Coated (Al) \\
\cline { 2 - 4 } & - & - & - \\
\hline 0 & 10.71 & 0.76 & 0.10 \\
\hline 30 & 11.77 & 0.79 & 0.16 \\
\hline 60 & 17.53 & 1.21 & 0.29 \\
\hline 90 & & & \\
\hline
\end{tabular}
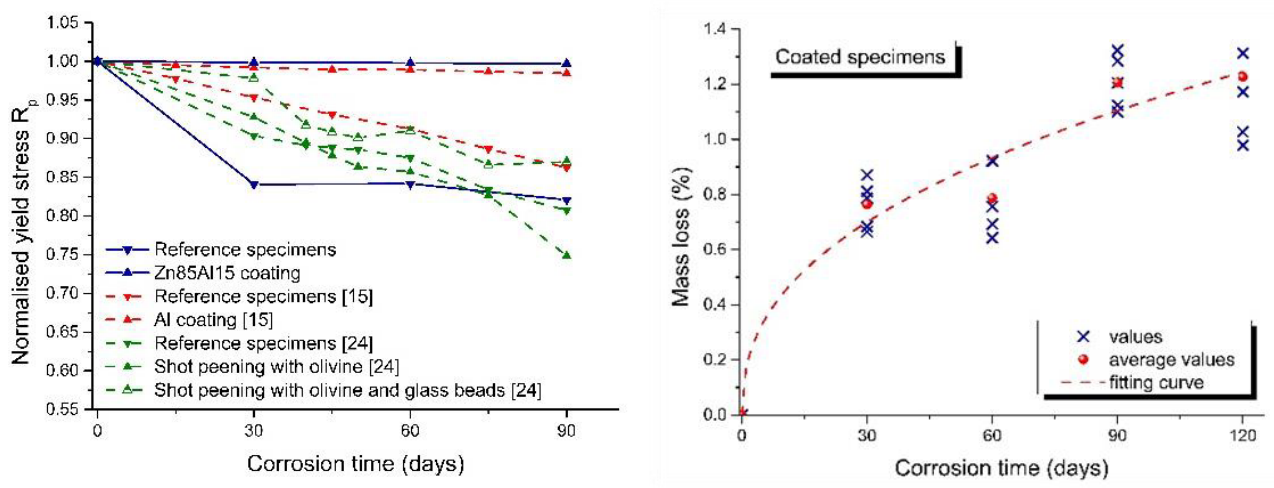

Fig. 4. (a) Percentage mass loss of all specimens (b) Mass loss rate in relation to the accelerated corrosion exposure time for coated with Zn85Al15 specimens

Figure 4 depicts the percentage mass loss of coated and shot-blasted specimens in relation to their reference, as the case may be. Mass loss of coated specimens is less than $1.5 \%$ for the entire testing time, whereas the bare specimens showed approximately $18 \%$ mass loss (about 14 times greater) by the end of 90-day exposure time. This highlights the significant influence of coating to the corrosion resistance. Furthermore, shot blasted specimens do not demonstrate the same corrosive resistance, but a slower degradation rate of mass loss, in respect to their reference. 

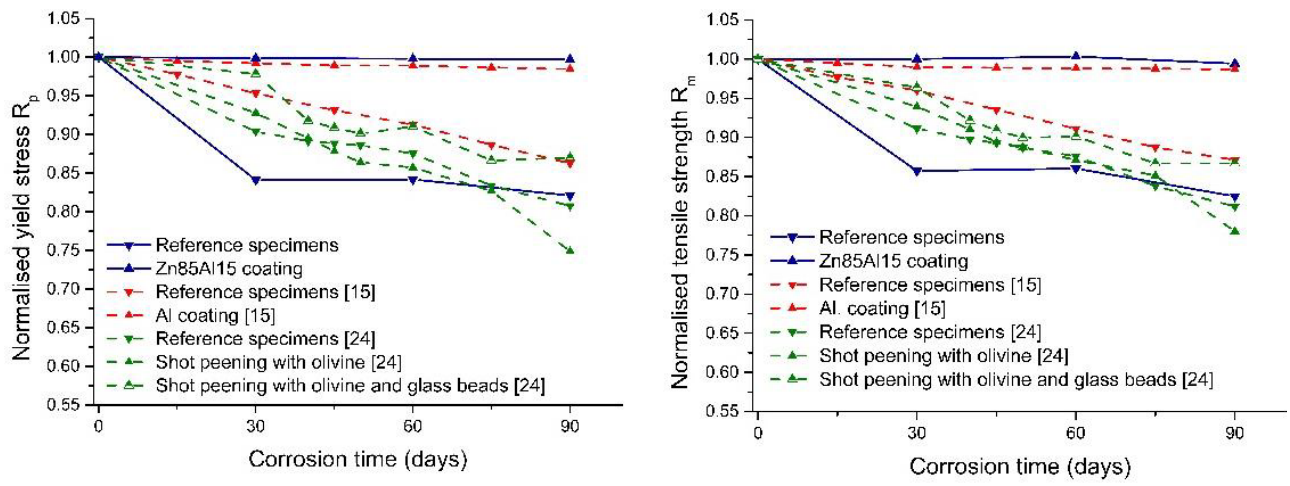

Fig. 5. (a) Normalised yield stress $R_{p}$ and (b) Normalised tensile strength $R_{m}$ in respect to corrosion exposure time for all groups of specimens

In continuance, the observations extracted from Figure 5 highlight the comforting effect of surface coating, in respect to yield stress and tensile strength. Coated specimens (for both cases of coatings) maintain their bearing capacity (tensile strength and yield stress) since they demonstrate almost zero mass loss.
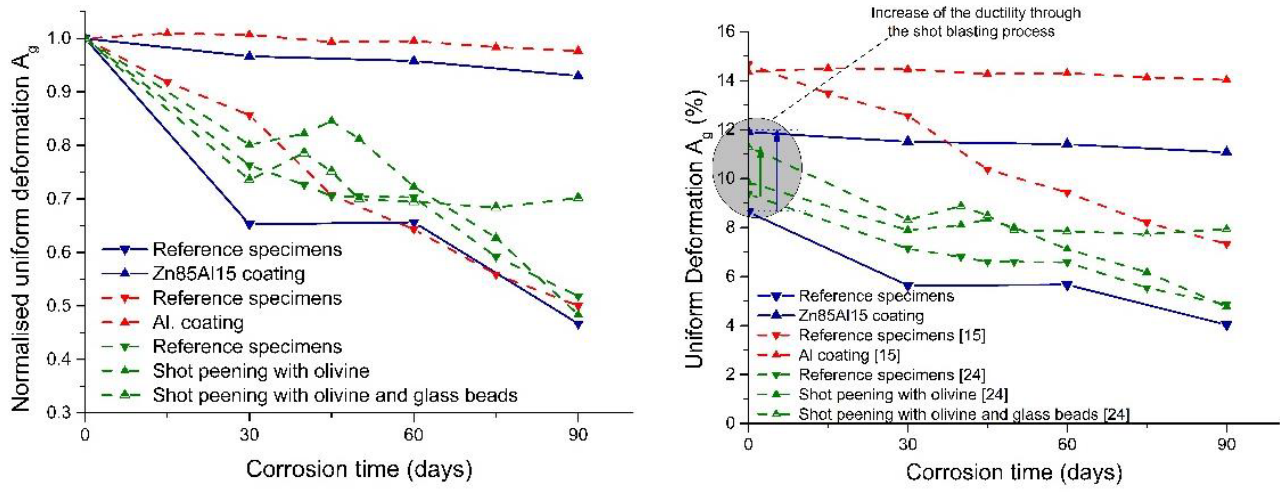

Fig. 6. (a) Normalised uniform deformation $A_{g}$ and (b) degradation of uniform deformation $A_{g}$ in respect to corrosion exposure time for all groups of specimens

Having regard to ductility, in terms of uniform deformation $A_{g}$, as shown in Figure 6, corresponding to maximum force, the shot blasting process prior to coating, demonstrates an increase of ductility. In the diagram at right, it can be noticed that the value of deformation in maximum strength in bare specimens, after a 60 -day corrosion exposure, is found below the lowest limits the set regulations $(<7.50 \%)$ for high ductile steel. As a matter of fact, shot peening application on steel causes a plastic surface deformation, which leads to a surface compression of the material. This compression results in the sealing of the exposed, to the environment, corrosion paths.

The abovementioned outcomes are in good agreement with other experimental studies, which have indicated the significant impact of corrosion on ductility properties of steel bars, contrary to the reduction of bearing capacity, in terms of strength, where the drop is broadly in line with the recorded percentage mass loss.

\section{Conclusions}


The following conclusions are drawn from the present study:

- Both cases of coating ( $\mathrm{Zn} 85 \mathrm{Al15}$ and $\mathrm{Al}$ ) provide satisfactory corrosion resistance since a minor percentage mass loss is recorded for the entire corrosion time.

- Purification of the steel surface with the use of combining shot blasting process, appears to significantly delay the degradation caused by corrosion in the case of salt spray chamber, as well as to keep the mechanical properties in a satisfying level, for quite a long exposure period.

- Shot peening process application on structural steel acts positively during a reasonable period of time. However, due to the "nature" of this process, the desirable plastic deformation, which is pursued through the shot peening process, inevitably causes rapid surface aging to the material. As a result, after a predetermined corrosion period, the defense of the material gets abolished and the temporarily hidden corrosion paths get reactivated. Consequently, the material is exposed again to the aggressive factors.

- It becomes clear enough that shot peening process needs further investigation and that it can be used as a possible anti-corrosion method for concrete reinforcement steel bars. Yet, the implementation to industrial materials from scrap appears not to be beneficial.

\section{References}

1. Hou, B.; Li, X.; Ma, X.; Du, C.; Zhang, D.; Zheng, M.; Xu, W.; Lu, D.; Ma, F. The cost of corrosion in China. Mater. Degrad. 2017, 1, 1-10.

2. Koch, G.; Varney, J.; Thompson, N.; Moghissi, O.; Gould, M.; Payer, J. International Measures of Prevention, Application, and Economics of Corrosion Technologies Study; NACE International: Houston, TX, USA, 2016.

3. Marcus, P. Pour un monde durable: Journée mondiale de la corrosion, 24 April 2020. Matér. Tech. 2020, 108, N1.

4. Darwin, D.; Kahrs, J.T.; Locke, C.E., Jr. Evaluation of Corrosion Resistance of Type 304 Stainless Steel Clad Reinforcing Bars; SM Report No. 65; The University of Kansas Center for Research, Inc.: Lawrence, KS, USA, 2001; 76p. 11.

5. Apostolopoulos, C.A. The influence of Corrosion and Cross- Section Diameter on the Mechanical Properties of B500c Steel. J. Mater. Eng. Perform. 2008, 18, 190-195.

6. Apostolopoulos, C.A. Mechanical behavior of corroded reinforcing steel bars S500s tempcore under low cycle fatigue. Constr. Build. Mater. 2007, 21, 1447-1456.

7. Salvatore, W.; Caprili, S.; Braconi, A.; Finetto, M.; Bianco, L.; Ascanio, C.; Moersch, J.; Apostolopoulos, C.A.; Ferreira Pimenta, G. Effects of Corrosion on Low-Cycle Fatigue (Seismic) Behaviour of High-Strength Steel Reinforcing Bars (RUSTEEL) RFSR-CT2009-00023-Technical Steel Research Series EUR 26687; European Commission-Directorate General for Research: Brussels, Belgium, 2014.

8. Andisheh, K.; Scott, A.; Palermo, A.; Clucas, D. Influence of chloride corrosion on the effective mechanical properties of steel reinforcement. Struct. Infrastruct. Eng. 2019, $15,1036-1048$.

9. Meda, A.; Mostosi, S.; Rinaldi, Z.; Riva, P. Experimental evaluation of the corrosion influence on the cyclic behaviour of RC columns. Eng. Struct. 2014, 76, 112-123.

10. Rajput, A.S.; Sharma, U.K. Corroded reinforced concrete columns under simulated seismic loading. Eng. Struct. 2018, 171, 453-463. 
11. Apostolopoulos, C.A.; Drakakaki, A.; Basdeki, M. Seismic assessment of a reinforced concrete column under seismic loads. Int. J. Struct. Integr. 2019, 10, 41-54.

12. Guo, A.X.; Li, H.T.; Ba, X.; Guan, X.C.; Li, H. Experimental investigation on the cyclic performance of reinforced concrete piers with chloride-induced corrosion in marine environment. Eng. Struct. 2015, 105, 1-11.

13. Angst, U.M.; Elsener, B. The size effect in corrosion greatly influences the predicted life span of concrete infrastructures. Sci. Adv. 2017, 3, e1700751.

14. Kumar, R.; \& Kumar, S. Thermal spray coating: a study. international journal of engineering sciences \& research technology, 7(3), 610-617, 2018

15. Diamantogiannis, G.; Apostolopoulos, Ch. Alk. and Nikolakopoulos, P.G. Mechanical Behavior of B500c Steel with an Aluminum Layer Coating in a Marine Environment, Journal of Materials in Civil Engineering, 27, 4

16. Gulec et al, Accelerated corrosion behaviors of $\mathrm{Zn}, \mathrm{Al}$ and $\mathrm{Zn} / 15 \mathrm{Al}$ coatings on a steel surface, MTAEC9, 45 (5), pg. 477-482 (2011)

17. Bobzin et al, Designing the corrosion products of ZnAl15: a new approach to smart corrosion protection coatings

18. Büteführ, M. (2007), Zinc-Aluminium-Coatings as Corrosion Protection for Steel. Materials and Corrosion, 58: 721-726. https://doi.org/10.1002/maco.200704058

19. ASTM. (1997). Standard practice for operating slat spray (fog) apparatus. B117, West Conshohocken, PA.

20. ASTM International. ASTM G1-03, Standard Practice for Preparing, Cleaning, and Evaluating Corrosion Test Specimens; ASTM International: West Conshohocken, PA, USA, 2017.

21. ISO. ISO 15630-1:2010, Steel for the Reinforcement and Prestressing of ConcreteTest Methods-Part 1: Reinforcing Bars, Wire Rod and Wire; ISO: Geneva, Switzerland, 2010.

22. Drakakaki, A.; Apostolopoulos, C. A.; Koulouris, K. Mechanical Characteristics of dual-phase steel B500c after shot peening process, Third International Conference on Advances in Civil, Structural and Construction Engineering - CSCE 2015, 10-11 December 2015, Rome, Italy

23. Drakakaki, A.; Apostolopoulos, C. A.; Katsaounis, A.; Bjorn, H. Corrosion resistance and mechanical characteristics of dual-phase steel B500c, after shot blasting processes, International Journal of Structural Integrity 8 (5), 544-564, 2017 